\title{
INFLUÊNCIA DA ADUBAÇÃO NO CRESCIMENTO VEGETATIVO DE CAFEEIROS NA AMAZÔNIA SUL OCIDENTAL
}

\author{
Danielly Dubberstein ${ }^{1}$, Fabio Luiz Partelli², \\ Jairo Rafael Machado Dias ${ }^{3}$, Marcelo Curitiba Espindula ${ }^{4}$
}

(Recebido: 05 de maio de 2016; aceito: 06 de outubro de 2016)

\begin{abstract}
RESUMO: O conhecimento do padrão de crescimento do cafeeiro torna-se fundamental para auxiliar no manejo da lavoura, em virtude da ocorrência de sazonalidade de crescimento ao longo do ano. Objetivou-se avaliar o crescimento vegetativo de ramos de cafeeiro situados na Amazônia Sul Ocidental em plantas adubada e não adubada. O experimento foi conduzido em lavoura clonal, com delineamento de blocos casualizados com três repetições,em esquema de parcelas subdivididas no tempo. As parcelas principais foram constituídas por plantas adubadas e não adubadas e as subparcelas acomodaram as épocas de avaliação (medições). As análises de crescimento dos ramos ortotrópico e plagiotrópico foram mensuradas a cada 14 dias, de maio de 2013 a junho de 2014, a partir disso estimou-se a taxa diária de crescimento vegetativo. Os dados foram submetidos à análise de variância e as médias comparadas pelo teste de Tukey. A adubação proporcionou maior crescimento aos ramos ortotrópico e plagiotrópico durante o período de outubro a dezembro. Averiguaram-se variações sazonais de crescimento ao longo do ano, com as maiores taxas incidindo de meados de setembro ao início de abril, quando ocorre maior parte da precipitação pluviométrica na região. Para um manejo nutricional eficiente, recomenda-se atenção especial ao parcelamento da adubação neste período.
\end{abstract}

Termos para indexação: Coffea canephora, análise de crescimento, variações sazonais, nutrição mineral.

\section{INFLUENCE OF FERTILIZATION ON COFFEE TREES VEGETATIVE GROWTH IN WEST SOUTH AMAZON}

\begin{abstract}
The standard of knowledge of coffee growth is fundamental to assist in the management of crop, due to the growth of seasonal occurrence throughout the year. The objective was to evaluate the vegetative branches growth of coffee located in South Western Amazon in fertilized and unfertilized plants. The trial was carried out in clonal tillage in a randomized block design with three replicates in time split plot. The main plots were fertilized and unfertilized plants and subplots accommodated the evaluation times (measurements). Evaluations of orthotropic and plagiotropic branches growth and were measured every 14 days, from May 2013 to June 2014, as it was estimated daily rate of vegetative growth. Data were submitted to analysis of variance and means were compared by Tukey test. Fertilization provided higher growth to orthotropic and plagiotropic branches during the period from October to December. Seasonal variations in growth are ascertained along the year, with the highest rates focusing mid-September to early April, when there is bulk of the rainfall in the region. For efficient nutrient management, it is recommended special attention the installment payment of fertilization in this period.
\end{abstract}

Index terms: Coffea canephora, growth analysis, seasonal variations, mineral nutrition.

\section{INTRODUÇÃO}

No gênero Coffea spp. são encontrados pelo menos 124 espécies, no entanto, economicamente somente o Coffea arabica L. (cafeeiro arábica) e o Coffea canephora Pierre ex A.Froehner (cafeeiro robusta ou conilon) são cultivados comercialmente em maior proporção (DAVIS et al., 2011).O Brasil destaca-se no cenário mundial como maior produtor e exportador de café, bem como o segundo maior produtor da espécie $C$. canephora. Localizado na Amazônia o Estado de Rondônia, se caracteriza como segundo maior produtor nacional de "Robusta" e apresenta grande potencial de expansão (COMPANHIA NACIONAL DEABASTECIMENTO-CONAB, 2015).

A escolha de cultivares recomendadas para a região, mudas sadias e vigorosas, seleção e preparo da área para o plantio, implantação de quebra-ventos e condução adequada das plantas, são algumas das técnicas que devem ser empregadas desde a formação do cafeeiro e geridas durante toda vida útil da lavoura (FERRAREZI et al., 2015; PINTO et al., 2013;VILLELA et al., 2015). A busca por conhecimentos sobre o padrão de crescimento da planta é relevante para

\footnotetext{
${ }^{1}$ Universidade Federal do Espírito Santo - Centro de Ciências Agrárias - Alto Universitário - s/no - 29.500-000 - Alegre - ES dany_dubberstein@hotmail.com

${ }^{2}$ Universidade Federal do Espírito Santo - Centro Universitário Norte do Espírito Santo - Rodovia BR 101 Norte - Km 60 Bairro Litorâneo - 29.932-540 - São Mateus - ES - partelli@yahoo.com.br

${ }^{3}$ Universidade Federal de Rondônia - Avenida Norte Sul - no 7300 - Bairro Nova morada - 76.940-000 - Rolim de Moura - RO jairorafaelmdias@hotmail.com

${ }^{4}$ Embrapa Rondônia - BR 364 - km 5,5 - Zona Rural - 76815-800 - Porto Velho - RO - marcelo.espindula@embrapa.br
}

Coffee Science, Lavras, v. 12, n. 2, p. 50 - 59, abr./jun. 2017 
um manejo adequado, pois esta característica está diretamente vinculada à produção. A produção de grãos do cafeeiro se dá em gemas novas, e a emissão de gemas depende do alongamento dos ramos plagiotrópicos e a emissão de novos ramos plagiotrópicos depende do crescimento do ramo ostotrópico. Desta forma, o potencial de produção do ano seguinte fica condicionado ao potencial de crescimento destes ramos (PEREIRA et al., 2007; SOUZA et al., 2013).

O crescimento vegetativo apresenta periodicidade sazonal ao longo do ciclo, com período de taxas elevadas e períodos de retardo. Relata-se que umas das principais causas da sazonalidade de crescimento são as variações climáticas, sendo que altas e baixas temperaturas, como também, chuva e estiagem comprometem o desenvolvimento do cafeeiro. Além disso, a frutificação, ciclo de maturação dos genótipos, idade dos ramos, estado nutricional da planta e manejo da adubação podem atuar sobre o crescimento do cafeeiro (AMARAL et al.,2007; AMARAL; RENA; AMARAL, 2006; FERREIRA et al., 2013; PARTELLI et al., 2010, 2013; RAMALHO et al., 2014; RAMOS et al., 2010; RODRIGUES et al., 2016).

Diante da necessidade de compreensão, estudos sobre as flutuações sazonais de crescimento do cafeeiro têm sido realizada nas principais regiões produtoras da espécie arábica (AMARAL; RENA; AMARAL, 2006; FERREIRA et al., 2013) e conilon (PARTELLI et al., 2010, 2013, COVRE et al., 2016) e através disso busca-se melhorias para algumas práticas de manejo, como a adubação mineral (PEREIRA et al., 2014), pois o fornecimento dos fertilizantes deve coincidir com o período de maior demanda de nutrientes para sustentar o crescimento vegetativo e a frutificaçãodo cafeeiro (LAVIOLA et al., 2006, 2008), resultando em uma melhor absorção eaproveitamento pela planta.

De acordo com Valadares et al. (2013) a demanda por cada nutriente em especifico varia de acordo com estágio do cafeeiro, o potássio $\left(\mathrm{K}_{2} \mathrm{O}\right)$, por sua vez, é mais exigido quando há alta produtividade, devido sua maior importância na fase reprodutiva, se caracterizando como o macronutriente mais exportado nos frutos. Já o nitrogênio $(\mathrm{N})$ tem alta demanda durante todo o ciclo, devido sua participação em todos os processos da planta, acompanhando o incremento de biomassa.

Diante da importância social e econômica da cafeicultura, das características climáticas da Amazônia e da lacuna de conhecimentos técnico e científico sobre o cultivo de cafeeiro nestas condições, objetivou-se avaliar o comportamento do crescimento vegetativo de ramos plagiotrópicos e ortotrópico de $C$. canephora cultivados na Amazônia Sul Ocidental em condições de solo adubado e não adubado.

\section{MATERIAL E MÉTODOS}

O experimento foi conduzido na Amazônia Sul Ocidental, no município de Rolim de Moura, localizado na zona da mata do estado de Rondônia, com altitude média de 277 metros, latitude de $11^{\circ} 49^{\prime} 43^{\prime \prime} \mathrm{S}$ e longitude $61^{\circ} 48^{\prime} 24^{\prime \prime} \mathrm{O}$. O clima predominante na região é Tropical Úmido Chuvoso - Am (Köppen), com temperatura média anual de $26^{\circ} \mathrm{C}$ e precipitação pluviométrica média de 2000 $\mathrm{mm}$ ano $\mathrm{o}^{-1}$. O período chuvoso está compreendido entre os meses de setembro/outubro até abril/maio. $\mathrm{O}$ primeiro trimestre do ano apresenta o maior acúmulo de chuvas. O período mais quente ocorre entre os meses de agosto a outubro (ALVARES et al., 2014).

Os valores médios de temperatura mínima, média, máxima, precipitação pluviométrica, ocorridos durante período experimental foram coletados na estação meteorológica da Universidade Federal de Rondônia localizada no mesmo município e estão expostos na Figura 1. O solo do local é classificado como Latossolo Vermelho-Escuro Eutrófico, textura argilosa (SANTOS et al., 2013), com relevo plano. Previamente à instalação do experimento foi feita a análise de solo de 0 a $40 \mathrm{~cm}$ de profundidade, cujo resultado está inserido na Tabela 1.

O estudo foi conduzido em lavoura de cafeeiro propagado por estacas, com dois anos e meio de idade, no espaçamento de quatro metros entre linhas e um metro entre plantas (2500 plantas por hectare). O delineamento experimental empregado foi de blocos casualizados em esquema de parcelas subdivididas no tempo. As parcelas principais foram constituídas por plantas adubadas e não adubadas;as subparcelas acomodaram os períodos de medições dos ramos.

O manejo de adubação do tratamento com plantas adubadas foi realizado de acordo com a recomendação para a cultura, aplicando-se $440 \mathrm{~kg}$ ha $^{-1}$ de N, $270 \mathrm{~kg} \mathrm{ha}^{-1}$ de $\mathrm{K}_{2} \mathrm{O}, 90 \mathrm{~kg} \mathrm{ha}^{-1}$ de $\mathrm{P}_{2} \mathrm{O}_{5}$, $80 \mathrm{~kg} \mathrm{ha}^{-1}$ de Ca e $40 \mathrm{~kg} \mathrm{ha}^{-1}$ de S. O nitrogênio foi fornecido na forma deureia e o potássio na forma de cloreto de potássio (KCL), estes foram parcelados em quatro aplicações (12/07 e 22/10/2013, 31/01e 28/02/2014). 


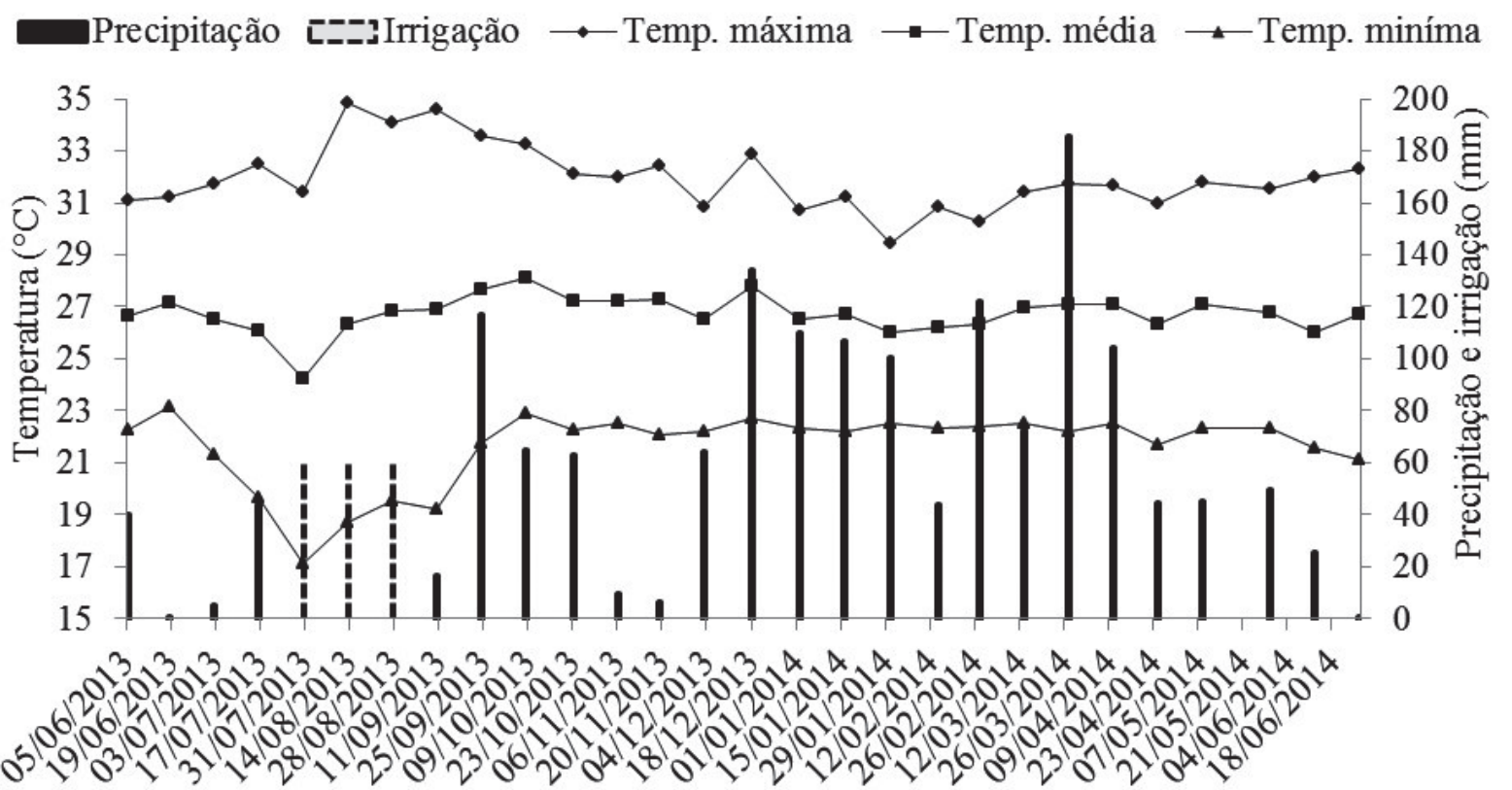

FIGURA 1 - Dados de precipitação pluviométrica, irrigação, temperatura mínima, média e máxima ocorridos durante o período da condução do experimento.

TABELA 1 - Resultados da análise química de solo na área experimental nas profundidades de 0 a $40 \mathrm{~cm}$.

\begin{tabular}{rrrrrrrrrr}
\hline & $\mathrm{pH}$ & $\mathrm{P}$ & $\mathrm{K}$ & $\mathrm{Ca}$ & $\mathrm{Mg}$ & $\mathrm{Al}+\mathrm{H}$ & $\mathrm{Al}$ & $\mathrm{MO}$ & $\mathrm{V}$ \\
\hline Amostra & em água & $\mathrm{mg} \mathrm{dm}^{-3}$ & \multicolumn{7}{c}{$\mathrm{mmol}_{\mathrm{c}} \mathrm{dm}^{-3}$} \\
$00-10 \mathrm{~cm}$ & 7,2 & 86 & 19,23 & 66,1 & 17,2 & 18,2 & 0,0 & 34,5 & 85 \\
$10-20 \mathrm{~cm}$ & 7,3 & 45 & 8,21 & 69,7 & 8,4 & 11,6 & 0,0 & 17,8 & 87 \\
$20-30 \mathrm{~cm}$ & 6,9 & 13 & 5,03 & 41,8 & 7,6 & 24,8 & 0,0 & 17,8 & 69 \\
$30-40 \mathrm{~cm}$ & 6,7 & 3 & 6,41 & 26,2 & 6,6 & 16,5 & 0,0 & 16,1 & 70 \\
\hline
\end{tabular}

pH: em $\mathrm{H}_{2} \mathrm{O}$ 1:2,5; P e K: Extração: Mehlich1; Ca e Mg: Extração: KCI 1mol/L; Al+H: Titulação; MO: Método Embrapa.

O fósforo, enxofre e cálcio na forma de superfosfato simples, foram aplicados em uma única vez (12 de julho de 2013). Para o tratamento não adubado fez-se a suspensão da adubação durante a condução da pesquisa. Em períodos de estiagem realizou-se a irrigação por aspersão convencional (Figura 1).

Cada tratamento contou com três blocos constituídos por 11 plantas, nestas plantas foram selecionados e identificados dois ramos, sendo um ortotrópico e outro plagiotrópico no dia 22 de maio de 2013. O ramo ortotrópico foi marcado a partir da base do ramo plagiotrópico selecionado, utilizando como critérios de escolha os ramos novos com elevada atividade de crescimento vegetativo. No dia 03 de dezembro de 2013 fez- se a marcação de um novo ramo plagiotrópico para ser medido, devido à perda de vigor do ramo selecionado primeiramente (PARTELLI et al., 2010).

As mensurações dos ramos foram feitas em intervalo de 14 dias, com início no dia 22 de maio de 2013 e o término em 24 de junho de 2014, estas foram feitas com auxílio de trena, aferindo da base demarcada até o ápice do ramo. Para o primeiro grupo de ramos totalizou-se 28 avaliações; o segundo ramo plagiotrópico foi avaliado no período de dezembro de 2013 a junho de 2014, totalizando 14 avaliações.

A partir dos dados obtidos calculou-se a taxa diária de crescimento vegetativo dos ramos plagiotrópicos e ortotrópico, fazendo a subtração 
do tamanho do ramo no mês atual pelo mês anterior, e dividindo a diferença pelo número de dias entre cada avaliação. Os dados foram submetidos à análise de variância e as médias comparadas pelo teste de Tukey através de programa estatístico, e a elaboração dos gráficos foi feita em planilha eletrônica.

\section{RESULTADOS E DISCUSSÃO}

A adubação empregada foi eficaz sobre as taxas de crescimento dos ramos ortotrópico e plagiotrópico do primeiro grupo selecionado em alguns períodos, ocasionando assim, interação significativa entre adubação e época de avaliação. No entanto, verifica-se comportamento distinto para $\mathrm{o} 2^{\circ}$ ramo plagiotrópico, que exibiu crescimento similar entre plantas adubadas e não adubadas, $\operatorname{logo}$, não diferiu estatisticamente (Tabela 2).

No período de 23 de outubro a 03 de dezembro de 2013 para o ramo ortotrópico, e 08 de outubro a 19 de novembro de 2013 para o ramo plagiotrópico as plantas adubadas apresentaram crescimento superior, chegando a acrescentar cerca de um milímetro diariamente em comparação a plantas não adubadas. Esses dados estão ilustrados na Figura 2, onde letras "a" e "b" distinguem as médias dos tratamentos, ramos adubados e não adubados, respectivamente.

Sob essas condições favoráveis de fornecimento de nutrientes aos cafeeiros resultados promissores tendem a ser esperados, já que todos têm funções substanciais no crescimento e desenvolvimento da planta. E, quando há ocorrência de desequilíbrio entre macro e micronutriente no solo ou até mesmo a deficiência destes, podem acarretar danos ao crescimento, à morfologia, anatomia e a composição química das plantas (PEREIRA; SOUZA; GODOI, 2014; TAIZ; ZAIGER, 2010), assim como, perdas em produção.

Respostas positivas no desenvolvimento vegetativo de cafeeiro foram verificadas por Souza et al.(2013), em função do uso de diferentes doses de NPK fornecidos através de fertirrigação e irrigação na formação de café arábica, com incrementos em diâmetro do caule, comprimento do primeiro ramo plagiotrópico e número de internódios. Assim como, Almeida et al. (2011), relataram maior tendência de desenvolvimento de mudas de cafeeiro com aplicação de solução organomineral composta por macro e micronutrientes, comelevado teor de nitrogênio $(12 \%)$.
Pesquisa de Carmo et al. (2014) avaliando diferentes fontes e doses de $\mathrm{P}$ em cafeeiro arábica obteve efeito positivo no desenvolvimento vegetativo em comparação ao controle, sendo que o adubo organomineral-Biorin ${ }^{\circledR}$ com dose de 400 $\mathrm{mg} \mathrm{kg-}{ }^{1}$ de $\mathrm{P}$ propiciou significativamente maiores teores de massa seca de parte aérea, massa seca de raiz, relação MSPA/MSR e massa seca total. Já, Ribeiro et al. (2009) verificou que a maior concentração de $\mathrm{K}$ (135 mg L- $\left.{ }^{1}\right)$ contida na água residuária de café contribuiu para o crescimento vegetativo do cafeeiro,em altura de planta e diâmetro do ramo ortotrópico.

Para os períodos em que o manejo nutricional não surtiu efeito no crescimento vegetativo do cafeeiro, pode-se atrelar a fertilidade natural do solo da área experimental, visto que a análise química indicou de forma geral, conteúdos satisfatórios de nutrientes, $\mathrm{pH}$ próximo a neutro, saturação por bases entre 69 e $87 \%$ e matéria orgânica mediana entre 16,1 e 34,5 $\mathrm{g} \mathrm{kg}^{-1}$ conforme classificação de Alvarezet al. (1999). Sendo assim, mesmo para plantas não adubadas, sugere-se que o solo foi capaz de suprir a demanda do cafeeiro neste período.

Ressalta-se que a área experimental contou com a adição de palha de café, oriunda do beneficiamento do grão. Como se sabe essa fonte de matéria orgânica melhora as propriedades físicas, físico-químicas, químicas e biológicas do solo. Além disso, auxilia no arejamento, na permeabilidade e na maior retenção de umidade no solo, fornece nutrientes, disponíveis às plantas lentamente e acresce a capacidade de troca de cátions (CTC) (FERNANDES et al., 2013), logo, pode ter contribuído positivamente para estes resultados.

$O$ padrão de crescimento do ramo ortotrópico (A) e plagiotrópico (B) mostrouse semelhante, assim como o segundo ramo plagiotrópico avaliado de dezembro a maio (C) (Figura 2). Entretanto, apresentaram variações no crescimento em função das épocas de avaliação ao longo do ano, fato confirmado através da análise estatística (Tabela 2).

Constatou-se que o crescimento vegetativo dos cafeeiros cultivados no estado de Rondônia apresenta variações sazonais ao longo do ano, independentemente da aplicação ou não de fertilizantes. Esses resultados corroboram com Ferreira et al. (2013) e Partelli et al. (2010, 2013), COVRE et al., (2016) pois também averiguaram periodicidade estacional do crescimento vegetativo do cafeeiro para demais regiões produtoras de café arábica e conilondo país. 
TABELA 2 - Resumo da análise de variância (ANOVA) para crescimento vegetativo do ramo ortotrópico, $1^{\circ}$ ramo plagiotrópico e $2^{\circ}$ ramo plagiotrópico.

\begin{tabular}{|c|c|c|c|}
\hline Fonte de Variação & Grau de liberdade & Soma de quadrado & $\mathrm{F}$ \\
\hline \multicolumn{4}{|c|}{ Ortotrópico } \\
\hline Manejo adubação (a) & 1 & 2,05 & $2,18^{\mathrm{ns}}$ \\
\hline Épocas avaliadas (b) & 27 & 154,70 & $50,44 * *$ \\
\hline Interação axb & 27 & 7,67 & $2,50 * *$ \\
\hline \multicolumn{4}{|c|}{$1^{\circ}$ Plagiotrópico } \\
\hline Manejo adubação (a) & 1 & 1,27 & $3,10^{\mathrm{ns}}$ \\
\hline Épocas avaliadas (b) & 27 & 273,94 & $77,03 * *$ \\
\hline Interação axb & 27 & 9,24 & $2,60 * *$ \\
\hline \multicolumn{4}{|c|}{$2^{\circ}$ Plagiotrópico } \\
\hline Manejo adubação (a) & 1 & 6,19 & $3,62^{\text {ns }}$ \\
\hline Épocas avaliadas (b) & 13 & 156,61 & $21,38 * *$ \\
\hline Interação axb & 13 & 4,94 & $0,67^{\mathrm{ns}}$ \\
\hline
\end{tabular}

As menores taxas de crescimento dos ramos ocorreram de junho ao início de outubro de 2013 e de abril a junho de 2014 (Figura 2). De acordo com Soares et al. (2005) e Souza et al. (2013) a redução no crescimento de ramos do cafeeiro resulta em menor produção de nós disponíveis para a formação de gemas, logo, ocasiona redução na produção de frutos. Portanto, há correlação positiva entre o crescimento vegetativo e números de nós emitidos por ramo.

A Amazônia Ocidental se caracteriza climaticamente com temperaturas elevadas praticamente em todo o ano, contudo, nos meses de agosto e setembro maior média de temperatura máxima foram registradas, chegando a $34^{\circ} \mathrm{C}$ (Figura 1). Dessa forma, possivelmente a temperatura máxima teve maior comprometimento no crescimento do cafeeiro do que a temperatura mínima. Distinguindo-se das demais regiões produtoras de café situadas no sudeste, sul e centrooeste do país, nas quais as baixas temperaturas são correlacionadas ao menor crescimento vegetativo do cafeeiro durante período de inverno (FERREIRA et al., 2013; PARTELLI et al., 2010, 2013).

Resultados semelhantes foram constatados por Amaral et al. (2007), verificando menores taxas de crescimento vegetativo de cafeeiro quando a temperatura máxima esteve acima de $32^{\circ} \mathrm{C}$ para a região sul do Espírito Santo. Partelli et al. (2010) verificaram taxas mais elevadas de crescimento vegetativo quando a média da temperatura máxima esteve abaixo de $31,5^{\circ} \mathrm{C}$ para as condições do Estado do Rio de Janeiro. Partelli et al. (2013) constataram redução nas taxas de crescimento quando ocorreram temperaturas acima de $34^{\circ} \mathrm{C}$ chegando alguns dias a alcançar $38^{\circ} \mathrm{C}$ no norte do Espírito Santo.

As temperaturas elevadas danificam membranas e enzimas, pois causam um aumento de fluidez de lipídeos de membranas e um decréscimo na força de ligação de hidrogênio e 
interações eletrostáticas entre grupo polares de proteínas na fase aquosa das membranas, com isso modificam a composição e a estrutura de membranas, bem como causa vazamento de íons (TAIZ; ZEIGER, 2010).

Estudos de Bunn et al. (2015), relatam que nos próximos anos em função das mudanças climáticas a cafeicultura nos estados de Rondônia e Espírito Santo pode ficar comprometida devido ao aumento da temperatura do ar. Por sua vez, Rodrigues et al. (2016), fundamentam que o cafeeiro conilon e arábica apresentam menor dano a elevada temperatura quando manejado em concentração atmosférica de $700 \mathrm{ppm}$ de $\mathrm{CO}_{2}$, uma vez que plantas com metabolismo $\mathrm{C} 3$ quando expostas a níveis elevados de $\mathrm{CO}_{2}$, aumentam as taxas de carboxilação pela Rubisco, devido à supressão do $\mathrm{O}_{2}$ no seu campo ativo, com isso otimizam o crescimento através da maior produção de fotoassimilados (BADER; SIEGWOLF; KÖRNER, 2010; KIRSCHBAUM, 2011).

Além da temperatura, a seca e baixa umidade relativa do ar colaboram para ocorrência de retardo nas taxas de crescimento (DAMATTA; RAMALHO, 2006). A região de estudo apresenta período de estiagem bem caracterizado, e associado a altas temperaturas tende a agravar substancialmente a situação do cafeeiro. Nos meses de maio a setembro foram registradas as menores quantidades de precipitação pluviométrica (Figura 1).

O déficit hídrico causa redução da área foliar, em consequência da abscisão foliar, da produção de folhas menores, ou até mesmo da redução da emissão de novas folhas. Refletindo também negativamente sobre o sistema radicular do cafeeiro, particularmente sobre as raízes absorventes que prejudicam ofluxo de água e minerais (MARTINS et al., 2006). Em estudo realizado por Ferreira et al. (2013), verificou menores taxa de crescimento de café arábica nas condições do cerrado de Goiás no período de estiagem típico da região (maio a setembro/ outubro) até mesmo em plantas irrigadas.

A partir de meados de setembro o crescimento vegetativo do primeiro grupo de ramos aumentou significativamente e as maiores ganhosse concentraram entre outubro e janeiro, incidindo com o período abundante em chuva. Observa-se uma leve queda do crescimento a partir do dia 23/10/13 e novo aumento a partir do dia 20/11/13 (Figura 2A e B) este comportamento pode estar correlacionado com pequeno déficit hídrico (veranico) ocorrido nesse intervalo (Figura 1). Os ramos plagiotrópicos mensurados a partir de dezembro apresentaram as maiores taxas de crescimento nos dois primeiros meses de avaliação, dezembro a janeiro (Figura 2C).

Resultados semelhantes foram encontrados por Amaral, Rena e Amaral (2006) e Partelli et al. (2013), constatando condição propicia para o crescimento do cafeeiro a partir dos meses de agosto e setembro, devido ao início do período chuvoso e a ocorrência de temperaturas adequadas. Relatos de Ferreira et al. (2013) e Nazareno et al. (2003) confirmam este evento, pois obtiveram surto de crescimento em plantas não irrigadas no período de outubro a dezembro, com a ocorrência do início das chuvas e aumento da temperaturas do ar atmosférico.

Quedas gradativas de crescimento iniciaram-se no mês de janeiro estendendo ao início de abril, para todos os ramos avaliados. Estes resultados podem ser elucidados pela frutificação do cafeeiro, uma vez que nas fases de granação e maturação há grande demanda de nutrientes para formação do mesmo, tornando-os drenos preferenciais por fotoassimilados (LAVIOLA et al., 2008; PARTELLI et al., 2014), remobilizando dos órgãos vegetativos e redistribuindo para os frutos. Com isso a concorrência por nutrientes durante o período de desenvolvimento dos frutos caracterizase como um fator de restrição ao crescimento vegetativo. Relata-se que taxas de crescimento de ramos primários são significativamente maiores em plantas com ausência de frutos (AMARAL; RENA; AMARAL, 2006; PARTELLI et al., 2013). Após a colheita dos frutos no final de abril, observou-se redução do crescimento dos ramos. Vincula-se a isto a área foliar, uma vez que a queda de folhas é intensificada com a colheita e período seco, diminuindo a capacidade fotossintética da planta. Comportamento similar foi constatado por Ferreira et al. (2013), que atribui como causa a perda das folhas em decorrência da colheita manual dos frutos. Todavia, pode-se associar este comportamento à redução da precipitação pluviométrica, como especificado anteriormente.

Quando correlacionadas as taxas de crescimento com as médias de precipitação verificou-se efeito significativo para os ramos avaliados nos dois tratamentos (plantas adubadas e não adubadas), confirmando a influência desta condição climática sobre o crescimento vegetativo do cafeeiro nas condições estudadas (Tabela 3 ). 

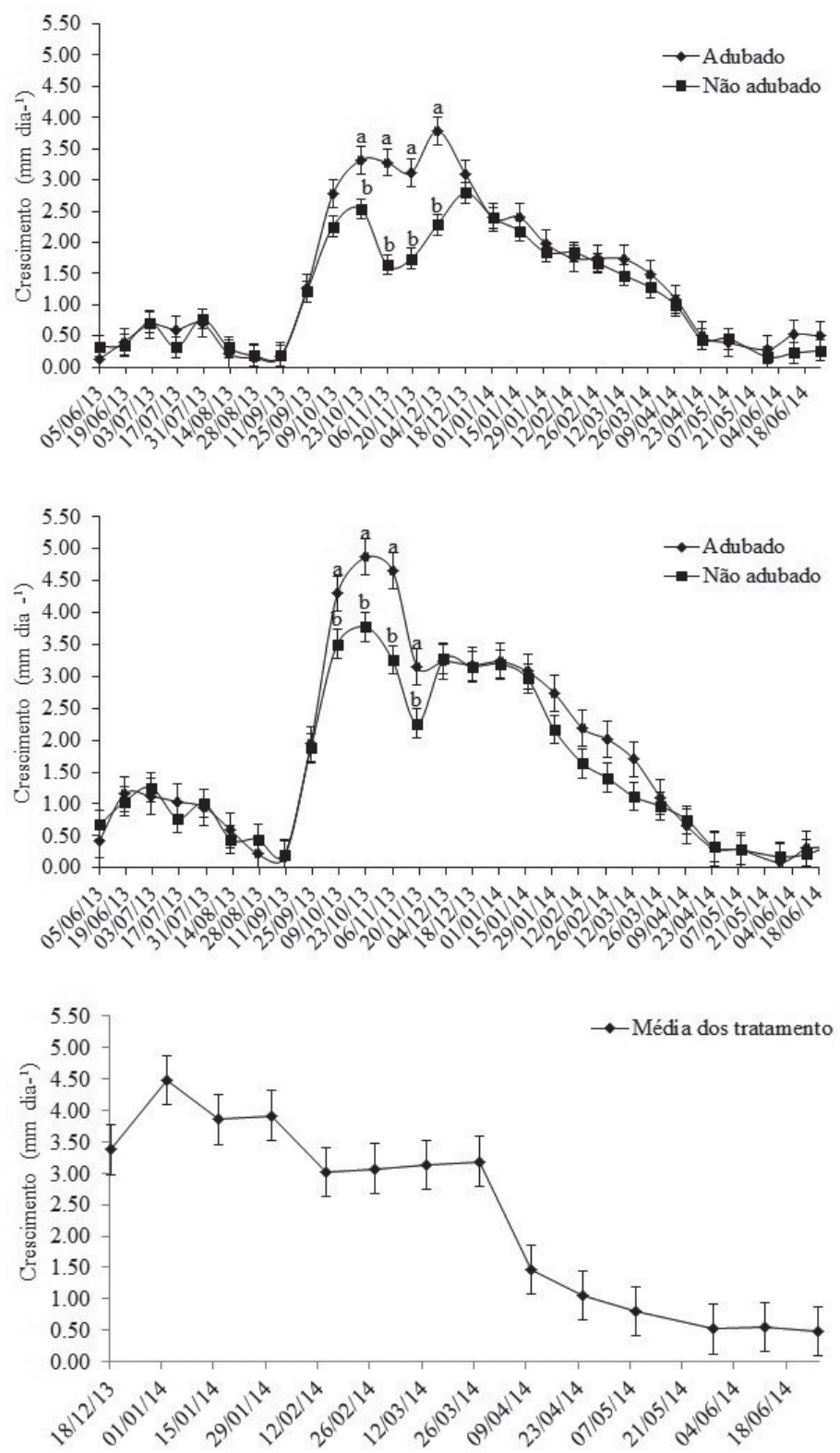

FIGURA 2 - Crescimento vegetativo de ramo ortotrópico (A), $1^{\circ}$ plagiotrópico (B) (mensurados de maio de 2913 a junho de 2014) e $2^{\circ}$ plagiotrópico (C) (mensurado de dezembro de 2013 a junho de 2014) de plantas de cafeeiros adubados e não adubados. As barras representam o erro padrão da média, e as letras "a" e "b" representam a diferença entre os tratamentos.

Em vista dos resultados averiguados, evidenciou-se que o cafeeiro demanda maiores quantidades de nutrientes no período compreendido entre meados de setembro ao início de abril, em função das maiores taxas de crescimento, bem como da frutificação, que se caracterizam com grande exigência nutricional. Assim, ressaltase que adubação mineral do cafeeiro, quando necessária, deve ser planejada de forma que a maior proporção dos fertilizantes seja fornecida neste período, para atender satisfatoriamente a demanda da planta. Com isso, irá ter uma maior eficiência no uso do fertilizante aplicado, refletindo diretamente sobre o retorno do investimento feito na aquisição dos adubos, bem como na produção da lavoura. 
TABELA 3 - Correlação entre a média da precipitação pluviométrica e a taxa de crescimento vegetativo dos ramos ortotrópico e plagiotrópicos do cafeeiro adubado e não adubado ao longo do período avaliativo.

\begin{tabular}{|c|c|c|}
\hline Correlação & Coeficiente de correlação (r) & Significância \\
\hline \multicolumn{3}{|c|}{ Ortotrópico } \\
\hline Precipitação x Crescimento ortotrópico adubado & 0,65 & $* *$ \\
\hline $\begin{array}{l}\text { Precipitação x Crescimento ortotrópico não } \\
\text { adubado }\end{array}$ & 0,76 & $* *$ \\
\hline \multicolumn{3}{|c|}{$1^{\circ}$ Plagiotrópico } \\
\hline $\begin{array}{c}\text { Precipitação x Crescimento } 1^{\circ} \text { plagiotrópico } \\
\text { adubado }\end{array}$ & 0,56 & $* *$ \\
\hline $\begin{array}{l}\text { Precipitação x Crescimento } 1^{\circ} \text { plagiotrópico não } \\
\text { adubado }\end{array}$ & 0,57 & $* *$ \\
\hline \multicolumn{3}{|c|}{$2^{\circ}$ Plagiotrópico } \\
\hline $\begin{array}{c}\text { Precipitação x Crescimento } 2^{\circ} \text { plagiotrópico } \\
\text { adubado }\end{array}$ & 0,86 & $* *$ \\
\hline $\begin{array}{l}\text { Precipitação x Crescimento } 2^{\circ} \text { plagiotrópico não } \\
\text { adubado }\end{array}$ & 0,90 & $* *$ \\
\hline
\end{tabular}




\section{CONCLUSÕES}

A adubação mineral proporciona maiores taxas de crescimento dos ramos plagiotrópicos e ortotrópico de cafeeiros em determinado período, para as condições estudadas.

Há ocorrência de variações sazonais de crescimento vegetativo ao longo do ano na Amazônia Sul Ocidental, com máximo crescimento entre meados de setembro ao início de abril, quando ocorre maior precipitação pluviométrica e média de temperatura máxima inferior a $33^{\circ} \mathrm{C}$.

A adubação mineral deve ser priorizada neste período, devido a maior exigência nutricional da planta para crescimento e produção.

\section{AGRADECIMENTOS}

Os autores agradecem a Universidade Federal do Espírito Santo (UFES), o Coordenador de Melhoramento do Pessoal de Ensino Superior (CAPES), a Universidade Federal de Rondônia (UNIR) e o protudor rural Ronildo Berger

\section{REFERÊNCIAS}

ALMEIDA, S.L.S. de et al. Fertilização foliarem mudas de cafeeiro com organominerais líquidos. Tecnologia \& Ciência Agropecuária, João Pessoa, v.5, n.3, p.913, set. 2011.

ALVARES, C. A. et al. Köppen's climate classification map for Brazil. Meteorologische Zeitschrift, Stuttgart, v. 22, n. 6, p. 711-728, Jan. 2014.

ALVAREZ, V. H. et al. Interpretação dos resultados das análises de solos. In: RIBEIRO, A. C.; GUIMARÃES, P. T. G.; ALVAREZ, V. H. (Ed.).Recomendações para o uso de corretivos e fertilizantes em Minas Gerais: $5^{\mathrm{a}}$ aproximação. Viçosa, MG: CFSEMG, 1999.p.289302.

AMARAL, J. A. T. do et al. Crescimento vegetativo e produtividade de cafeeiros conilon propagados por estacas em tubetes. Ciência e Agrotecnologia, Lavras, v.31, n.6, p.1624-1629, nov./dez. 2007.

AMARAL, J. A. T. do; RENA, A. B.; AMARAL, J. F. T. do. Crescimento vegetativo sazonal do cafeeiro e sua relação com fotoperíodo, frutificação, resistência estomática e fotossíntese. Pesquisa Agropecuária Brasileira, Brasília, v.41, n.3, p.377-384, mar. 2006.

BADER, M. K. F.; SIEGWOLF, R.; KÖRNER, C. Sustained enhancement of photosynthesis in mature deciduous forest trees after 8 years of free air $\mathrm{CO}_{2}$ enrichment. Planta, Berlin, v. 232, p. 1115-1125, Aug. 2010 .
BUNN, C. et al. A bitter cup: climate change profile of global production of Arabica and Robusta coffee. Climatic Change, Berlin, v. 129, n. 1, p. 89-101, 2015.

CARMO, D. L. et al. Crescimento de mudas de cafeeiro recém-plantadas: efeito de fontes e doses de fósforo. Coffee Science, Lavras, v. 9, n. 2, p. 196-206, abr./ jun. 2014.

COMPANHIA NACIONAL DE ABASTECIMENTO. Acompanhamento da safra brasileira de café, safra 2015, quarto levantamento. Disponível em: $\quad<$ http://www.conab.gov.br/OlalaCMS/uploads/ arquivos/15_12_17_09_02_47_boletim_cafe dezembro_2015_2.pdf>.Acessoem: 22 fev. 2016.

COVRE, A. M. et al. Vegetative growth of Conilon coffee plants under two water conditions in the Atlantic region of Bahia State, Brazil. Acta Scientiarum. Agronomy, Maringá, v. 38, n. 4, p. 535, Oct./Dec. 2016.

DAMATTA, F. M.; RAMALHO, J. D. C. Impacts of drought and temperature stress on coffee physiology and production: a review. Brazilian Journal of Plant Physiology, Campos dos Goytacazes, v. 18, n. 1, p. 5581, Jan./Mar. 2006.

DAVIS, A. P. et al. Growing coffee: Psilanthus (Rubiaceae) subsumed on the basis of molecular and morphological data: implications for the size, morphology, distribution and evolutionary history of Coffea. Botanical Journal of the Linnean Society, London, v. 167, n. 1, p. 357-377, 2011.

FERNANDES, A. L. T. et al. Redução da adubação mineral do cafeeiro com a utilização de palha de café. Coffee Science, Lavras, v. 8, n. 3, p. 324-336, jul./set. 2013.

FERRAREZI, R. S. et al. Crescimento de mudas de café sob diferentes preparo do solo e irrigação para agricultura familiar. Coffee Science, Lavras, v. 10, n. 1, p. 91-101, jan./mar. 2015.

FERREIRA, E. P. B. et al. Crescimento vegetativo de Coffea arabica L. influenciado por irrigação e fatores climáticos no Cerrado Goiano. Semina: CiênciasAgrárias, Londrina, v. 34, n. 6, p. 3235-3244, 2013.

KIRSCHBAUM, M. U. F. Does enhanced photosynthesis enhance growth?: lessons learned from $\mathrm{CO}_{2}$ enrichment studies. Plant Physiology, Rochville, v. 155, p. 117-124, Jan. 2011. 
LAVIOLA, B. G. et al. Acúmulo em frutos e variação na concentração foliar de NPK em cafeeiro cultivado em quatro altitudes. Bioscience Journal, Uberlândia, v. 24, p. 19-31,jan./mar. 2008.

Dinâmica de $\mathrm{N}$ e $\mathrm{K}$ em folhas, flores e $\overline{\text { frutos de }}$ cafeeiro arábico em três níveis de adubação. Bioscience Journal, Uberlândia, v. 22, n. 3, p. 33-47, set./dez.2006.

MARTINS, C. C. et al.Crescimento inicial do café conilon (Coffea canefora Pierre ex Froehner) sob diferentes lâminas de irrigação. Engenharia na Agricultura, Viçosa, v. 14, n. 3, p. 193-201, jul./ set.2006.

NAZARENO, R. B. et al. Crescimento inicial do cafeeiro Rubi em resposta a doses de nitrogênio, fósforo e potássio e a regimes hídricos. Pesquisa Agropecuária Brasileira, Brasília, v. 38, n. 8, p. 903910, ago. 2003.

PARTELLI, F. L. et al. Dry matter and macronutrient accumulation in fruits of conilon coffee with different ripening cycles. Revista Brasileira de Ciência do Solo, Viçosa, v. 38, n. 1, p. 214-222, 2014.

Seasonal vegetative growth in genotypes of Coffea canephora, as related to climatic factors. Journal of Agricultural Science, Toronto, v. 5, n. 8, p. 108-116, 2013.

Seasonal vegetative growth of different age branches of conilon coffee tree. Semina: Ciências Agrárias, Londrina, v. 31, n. 3, p. 619-626, 2010.

PEREIRA, A. A. et al. Descrição do crescimento vegetativo do cafeeiro cultivar Rubi MG 1192, utilizando modelos de regressão. Coffee Science, Lavras, v. 9, n. 2, p. 266-274, abr./jun. 2014.

PEREIRA, C. S.; SOUZA, F. L. F. de; GODOI, C. A. Aplicação de Extrato Etanólico de Própolis (EEP) na nutrição e desenvolvimento de mudas de cafeeiro. Coffee Science, Lavras, v. 9, n. 1, p. 14-23, jan./ mar.2014.

PEREIRA, S. P. et al. Crescimento vegetativo e produção de cafeeiros (Coffea arabica $\mathrm{L}$.) recepados em duas épocas, conduzidos em espaçamentos crescentes. Ciência e Agrotecnologia, Lavras, v. 31, n. 3, p. 643649, maio/jun. 2007.
PINTO, C. G. et al.Faixas críticas de teores foliares de macronutrientes primários para cafeeiros fertirrigados no primeiro ano pós-plantio. Coffee Science, Lavras, v. 8 , n. 4 , p. 530-538, out./dez.2013.

RAMALHO, J. C. et al. Cold impact and acclimation response of Coffea spp. plants. Theoretical and Experimental Plant Physiology, Campos dos Goytacases, v. 26, p. 5-18, 2014.

RAMOS, R. A. et al. Variação sazonal do crescimento vegetativo de laranjeiras Hamlin enxertadas em citrumeleiro Swingle no município de Limeira, Estado de São Paulo. Acta Scientiarum Agronomy, Maringá, v.32, n.3, p. 539-545, 2010.

RIBEIRO, M. S. et al. Efeitos de águas residuárias de café no crescimento vegetativo de cafeeiros em seu primeiro ano. Engenharia Agrícola, Jaboticabal, v.29, n.4, p.569-577, out./dez. 2009.

RODRIGUES, W. P. et al. Long-term elevated air $\left[\mathrm{CO}_{2}\right]$ strengthens photosynthetic functioning and mitigates the impact of supra-optimal temperatures in tropical Coffea arabica and C. canephora species. Global Change Biology, Oxford, v. 22, n. 1, p. 415431, Jan.2016.

SANTOS, H. G. dos et al. Sistema brasileiro de classificação de solos. 3.ed. Brasília,DF, EMBRAPA, 2013. 353 p.

SOARES, A. R. et al. Irrigação e fisiologia da floração em cafeeiros adultos na região da zona da mata de Minas Gerais. Acta Scientiarum. Agronomy, Maringá, v. 27, n. 1, p. 117-125, jan./mar.2005.

SOUZA, R. S. et al. Características de crescimento inicial de duas cultivares de cafeeiro sob diferentes regimes hídricos e níveis de fertilização NPK. Semina: Ciências Agrárias, Londrina, v. 34, n. 6, p. 3141-3152, 2013.

TAIZ, L.; ZEIGER, E. Plantphysiology. $5^{\text {th }}$ ed. Sunderland:Sinauer Associates, 2010.782 p.

VALADARES, S. V. et al. Produtividade e bienalidade da produção de cafezais adensados, sob diferentes doses de N e K. Pesquisa Agropecuária Brasileira, Brasília, v.48, n.3, p.296-303, mar. 2013.

VILLELA, G. M. et al. Faixas críticas de teores foliares de macronutrientes primários para cafeeiros fertirrigados em formação. Coffee Science, Lavras, v. 10, n. 3, p. 271-279, jul./set. 2015. 